\title{
Vitamin D (Calcifediol) Supplementation Modulates NGF and BDNF and Improves Memory Function in Postmenopausal Women: a Pilot Study
}

\author{
Flavio Pozzi ${ }^{1}$, Luigi Aloe ${ }^{2}$, Giovanni Vanni Frajese ${ }^{3}$ and Gaetano Frajese ${ }^{4}$ \\ ${ }^{1}$ Unit of Endocrinology - University of Rome Tor Vergata c/o San Giovanni Calibita Fatebenefratelli \\ Hospital, Rome, Italy \\ ${ }^{2}$ Institute of Cell Biology and Neurobiology, National Research Council, CNR NGF section Rome, \\ Italy \\ ${ }^{3}$ Faculty of Motor Sciences, University of Cassino, Cassino, Italy \\ ${ }^{4}$ Chair and Unit of Endocrinology, University of Rome Tor Vergata, Italy
}

Correspondence should be addressed to: Flavio Pozzi; flaviopozzi@libero.it

Received date: 27 June 2013; Accepted date: 19 September 2013; Published date: 9 December 2013

Academic Editor: Esther Pérez-navarro

Copyright (c) 2013. Flavio Pozzi, Luigi Aloe, Giovanni Vanni Frajese and Gaetano Frajese. Distributed under Creative Commons CC-BY 3.0

\begin{abstract}
1,25-dihydroxy vitamin D (vitamin D), a steroid hormone essential for calcium metabolism and various extra skeletal functions, is an in vitro inducer of Nerve Growth Factor (NGF) and modulates Brain-Derived Neurotrophic Factor (BDNF) in neurons, while its receptor is expressed in central nervous system. Due to restricted sunlight exposure and/or dietary intake many people are vitamin D-deficient and need supplementation. Vitamin D status has been associated with impairment in cognitive functions, but up to now no clinical studies have been conducted to verify its effect on neurotrophins and memory in humans. 20 postmenopausal women with low vitamin D levels were treated by calcifediol (25-OH D3) and followed in open for three months. At baseline and after three months NGF and BDNF together with Wechsler Memory Scale (WMS) were assessed. Mean plasma vitamin D levels were $14.52(+/-5.65 \mathrm{SD}) \mathrm{ng} / \mathrm{ml}$ at baseline and $47.58(+/-15.05 \mathrm{SD}) \mathrm{ng} / \mathrm{ml}$ after three months of supplementation. At the end of the study a statistical significant decrease in both neurotrophins was observed. NGF plasma levels were respectively: $451.13(+/-243.20 \mathrm{SD})$ $\mathrm{pg} / \mathrm{ml}$ and $323.68(+/-195.60 \mathrm{SD}) \mathrm{pg} / \mathrm{ml}(\mathrm{p}=0.05)$; BDNF levels were $431.10(+/-182.21$ $\mathrm{SD}) \mathrm{pg} / \mathrm{ml}$ and $366.25(+/-142.75 \mathrm{SD}) \mathrm{pg} / \mathrm{ml}(\mathrm{p}=0.02)$. WMS scored meanly $97.00(+/-$ 13.54 SD) at baseline and $107.82(+/-16.19$ SD) after three months $(\mathrm{p}=0.003)$. Considering the role of vitamin $\mathrm{D}$ in calcium metabolism and neurotrophic factors regulation, it seems indispensable in brain function and its deficiency must be considered in cognitive diseases.
\end{abstract}

Keywords: Vitamin D; calcifediol; NGF; BDNF; postmenopausal women 


\section{Introduction}

Vitamin D is a steroid hormone essential for maintaining calcium metabolism and various extra skeletal functions. Noteworthy, vitamin D controls more than 1000 genes, including those responsible for the regulation of cellular proliferation, differentiation, apoptosis and angiogenesis. As a result of restricted sunlight exposure and/or dietary intake, many people are vitamin D-deficient and need vitamin D supplements to meet their vitamin D requirement (Henry et al., 2010). Very frequently vitamin D insufficiency can occur with a number of potential consequences (Larrosa et al., 2001), many of which are still under investigation (Khazai et al., 2008; Cekic et al., 2009). Vitamin D supplementation acts to improve performance speed and proximal muscle strength, thus reducing the risk for falls (Bishoff-Ferrari et al., 2004 and 2012; Staud, 2005) and to prevent osteoporosis and fractures in post-menopausal women (Papadimitroupolos et al., 2002; BishoffFerrari et al., 2005; Brannon et al., 2008).

In addition to its well-established action in calcium homeostasis, vitamin D is being reconsidered as a neuroactive steroid (McGrath et al., 2001; McCann and Ames 2008; Eyles et al., 2009). The reported neuroprotective effects of vitamin $D$ include the in vitro biosynthesis of neurotrophic factors, the inhibition of nitric oxide synthase and increase in glutathione levels in the brain detoxification pathways (Garcion et al., 2002). Animal research indicates that vitamin D is crucial for brain development. Rats born to vitamin Ddeficient mothers have profound alteration in the brain at birth (e.g. enlarged lateral ventricles, reduced cortical thickness, increased cell proliferation) with low expression of NGF as reported by Evles et al., (2003). Even a transient hypovitaminosis D in early life can lead to persistent damage in the adult brain (Feron et al., 2005), along with dysregulation of oxidative phosphorilation, cytoskeleton maintenance, synaptic plasticity and neurotransmission (Evles et al., 2007; Lisak et al., 2009). As a matter of facts, vitamin D is a potent in vitro inducer of NGF mRNA expression in neural brain cells (Neveu et al., 1994a, Garcion et al., 2002) and protects the brain cortex against amyloid betainduced toxicity (Dursun et al., 2011), while, suppression of VDR in neuronal cultures disrupts L-type voltage-sensitive calcium channels and NGF production, increasing vulnerability to aging and neurodegeneration (Gezen-Ak et al., 2011). BDNF, a central player for synaptic and cognitive plasticity, is a protein related to NGF with some overlapping but not identical biological activities. Neurotrophic factors regulate neuronal differentiation, phenotype maintenance, and synaptic sprouting. They also protect adult neurons from mechanical, toxic or ischemic injuries and interfere in the death of neurons by necrosis or apoptosis (Siegel and Chauhan, 2000).

Vitamin D and its analogues have the ability to cross the blood brain barrier (Gascon Barre and Huet, 1983), and it has been shown that vitamin D receptor (VDR) and enzymes involved in bioactivation and catabolism of vitamin D are abundantly expressed in the brain neural cells, particularly in areas affected by neurodegenerative disorders (Neveu et al., 1994b; Eyles et al., 2005; McCann and James, 2008; Cekic et al., 2009).

In epidemiological studies, vitamin D status has been associated with impairments in cognitive functions such as memory, orientation, attention (Wilkins et al., 2006; Przybelski and Binkley, 2007; Llewellyn et al., 2009; Barnard and Colon-Emeric, 2010), executive function (Buell et al., 2009; Lee et al., 2009) and diagnosis of dementia (Buell et al., 2010). Kuningas et al., (2009) reported in elderly persons with cognitive impairment and in patients affected from Alzheimer disease a correlation between polymorphisms in VDR and age-dependent cognitive decline. In recent studies, the association of vitamin D deficiency with cognitive impairment was already confirmed (Annweiler et al., 2010; Slinin et al., 2010; Llewellyn et al., 2010 and 2011). Albeit the evidence of the role of vitamin D on neuronal and cognitive plasticity in animals, up to now, to our knowledge, no clinical studies have been conducted to verify the effect of vitamin $D$ on 
neurotrophin and memory in humans with normal cognitive functions.

\section{Patients and Methods}

Since the lack of data in humans, in order to investigate the effects of vitamin $\mathrm{D}$ on $\mathrm{NGF}$ and BDNF in a preliminary prospective interventional pilot clinical trial, we selected 20 postmenopausal women (age range 55-79 years) affected by osteopenia or osteoporosis ( $t$ score $<-1.0$ on lumbar and/or femoral densitometric DEXA assessment) with post-summer low plasma vitamin D levels due to scarce seasonal sunlight exposure. The study protocol was approved by the Ethics Committee of San Giovanni Calibita Fatebenefratelli Hospital of Rome, Italy. All procedures were carried out with the adequate understanding and written consent of the subjects.

All subjects required vitamin D supplementation according to WHO guidelines for osteoporosis (Genant et al., 1999). Exclusion criteria were other bone and calcium-phosphorus metabolism pathologies, hypoparathyroidism, renal insufficiency, intestinal and liver diseases, neoplastic diseases, neuropsychiatric disturbances, use of CNS acting drugs, corticosteroids and estrogen or vitamins supplementation. Other pharmacological therapies were allowed.

The subjects were enrolled from January to April and administered in open fashion for three months by means of calcifediol (25OH D3) (Didrogyl oral drops - Bruno Farmaceutici SpA) 8000 UI. (equivalent to 40 oral drops) once a week. Calcifediol is the main form of circulating vitamin $D$; it has hydrophilic properties and a half-life of 12-19 days, thus allowing a weekly administration (Stamp, 1974; Haddad and Rojanasathit, 1976).

At baseline and after three months plasma 25-OH vitamin D, calcium and phosphorus, NGF, BDNF were assessed. The last dose of calcifediol, after three months administration, has been taken 3-6 days before sampling. Plasma samples were collected at 8:00 am. To exclude secondary causes of altered calcium metabolism parathormone (PTH), calcitonin, osteocalcin, alkaline phosphatasis, blood count, protidogram and renal function were evaluated at baseline.

Vitamin D assay: Vitamin D and related hydroxilated metabolites were assessed by means of quantitative chemiluminescent immunoassay "LIAISON 25-OH D total assay (DiaSorin Inc. MN - USA)", measuring range was between $4-150 \mathrm{ng} / \mathrm{ml}$, with an inter-assay precision of $20 \% \mathrm{CV}$ (functional sensitivity). Haemolysis, dyslipidemia or hyperbilirubinemia do not affect assay performance. The measurement of $25-\mathrm{OH}$ vitamin $\mathrm{D}$ concentration in serum or plasma is the best indicator of vitamin D nutritional state. The optimal level of $25 \mathrm{OH}$ vitamin $\mathrm{D}$ is subject to some debate, but $>32 \mathrm{ng} / \mathrm{ml}$ (>80 nmol/L) is accepted as sufficient for bone health. Reference range for the classification of vitamin D status are $<10 \mathrm{ng} / \mathrm{ml}$ for deficiency; $10-30 \mathrm{ng} / \mathrm{ml}$ for insufficiency, $30-100 \mathrm{ng} / \mathrm{ml}$ for sufficiency, $>100 \mathrm{ng} / \mathrm{ml}$ for toxicity.

NGF assay: NGF levels were measured by a two-site immunoenzymatic assay kit (Promega Italia, MI, I)). Polystyrene 96-well microtubes immunoplates (Nunc) were coated with affinity purified polyclonal goat anti-NGF antibody, diluted in $0.05 \mathrm{M}$ carbonate buffer ( $\mathrm{pH}$ 9.6). To evaluate the non-specific signal parallel wells were coated with purified goat IgG (Zymed, San Francisco, CA, USA). After overnight incubation at $37{ }^{\circ} \mathrm{C}$ and $2 \mathrm{hrs}$ incubation with a blocking buffer $(0.05 \mathrm{M}$ carbonate buffer, pH 9.5, 1\% BSA), plates were washed three times with Tris- $\mathrm{HCl}, \mathrm{pH} 7.4$, $50 \mathrm{mM}, \mathrm{NaCl} 200 \mathrm{mM}, 0.5 \%$ gelatin, $0.1 \%$ Triton X-100. Then, samples and NGF standard solutions were diluted with sample buffer $(0.1 \%$ Triton X-100, $100 \mathrm{mM}$ Tris-HCl, pH 7.2, 400 mM NaCl, 4 mM EDTA, $0.2 \mathrm{mM}$ PMSF, $0.2 \mathrm{mM}$ benzethonium chloride, $2 \mathrm{mM}$ benzamidine, $40 \mathrm{U} / \mathrm{ml}$ aprotinin, $0.05 \%$ sodium azide, $2 \%$ BSA and $0.5 \%$ gelatine). After overnight the plates were washed and incubated with 4 $\mathrm{mU} /$ well anti-ß-NGF-galactosidase (Boehringer Mannheim, Germany) for 2 hours, and after additional washing $100 \mu \mathrm{l}$ of substrate solution $(4 \mathrm{mg} / \mathrm{ml}$ of chlorophenol red, Boehringer Mannheim, Germany, substrate buffer: 100mM HEPES, $150 \mathrm{mM} \mathrm{NaCl}, 2 \mathrm{mM} \mathrm{MgCl}_{2}, 0.1 \%$ sodium azide and 1\% BSA) were added. Using the Dynatech ELISA reader (Germany), optical 
density was measured at $575 \mathrm{~nm}$ after 2 hours. Values were corrected for nonspecific binding in standards and samples. The sensitivity was $3 \mathrm{pg} / \mathrm{ml}$, the recovery range of NGF was $80-90 \%$ and crossreactivity with other molecules of the NGF family (e.g. NT-3, NT-4/5) was less than $3 \%$. Data were represented as $\mathrm{pg} / \mathrm{mg}$ of protein (Weskamp and Otten,1987).

BDNF assay: BDNF levels were determined by a two-site enzyme immunoassay kit (Promega Italia, MI, I). 96-well immunoplates (NUNC) were coated each with $100 \mu \mathrm{l}$ of monoclonal anti-mouseBDNF antibody and incubated overnight at $4^{\circ} \mathrm{C}$. Then the plates were washed three times with buffer and incubated for 2 hrs shaking at $37{ }^{\circ} \mathrm{C}$. After another wash, the antigen was incubated and shaked for $2 \mathrm{hrs}$ with anti-human BDNF antibody. The plates were then washed and incubated for $1 \mathrm{hr}$ with anti-IgY HRP. After further washing the plates were incubated for $15 \mathrm{~min}$ with a TMB/Peroxidase substrate solution, then 1 M phosphoric acid (100 $\mu \mathrm{l} /$ well) was added. The colorimetric reaction was measured at $450 \mathrm{~nm}$ using the Dynatech MR 5000 ELISA reader (Germany). BDNF concentrations were assessed from the regression line for the BDNF standard (range 7.8-500 pg/ml-purified mouse BDNF) incubated in each assay under similar conditions. All assays were performed in triplicate. The assay sensitivity was $15 \mathrm{pg} / \mathrm{ml}$ of BDNF and cross-reactivity with other neurotrophic factors (e.g. NGF, NT-3 and NT-4) was less than 3\%. BDNF concentration was expressed as $\mathrm{pg} / \mathrm{g}$ wet weight for solid samples (Aloe et al., 1999).

Memory assessment: To examine whether vitamin D supplementation conditioned brain-related outcomes of memory, the Wechsler Memory Scale-revised (WMS-R) forms I and II (Wechsler D. 1945 and 1987) were administered at baseline and after three months. The WMS-R is a comprehensive evaluation of clinically relevant aspects of memory functioning commonly reported in individuals with suspected memory deficits. The scale includes seven subtests that evaluate mental control, logic, numeric, visual and association memory. The total score represents a mental index that takes into account the age of the subject. The scales were standardly administered by the same tester at the same time of the day (h 10:00 a.m.).

\section{Statistics}

In order to successively design an efficacy comparative trial, the primary end-point of this pilot study was to quantify the mean difference of neurotrophic factors plasma levels between the conditions of paucity and adequate vitamin D plasma levels. Since there is no data to effectively formulate the hypothesis we arbitrarily assume a standard deviation change of at least $65 \%$ (whatever it is) of mean neurotrophins plasma levels. Given this assumption and a $5 \%$ alpha level probability, with a group of 15 people an $80 \%$ possibility to test the change can be observed. Non-parametric Wilcoxon matched pairs signed ranks test (2-tailed significance) was conducted to evaluate the effect of vitamin D administration on neurotrophins and WMS-R. Due to the small number of enrolled subjects it was decided a-priori not to perform age groups and subtests analysis.

\section{Results}

Mean age of the subjects was 65.18 (+/7.08 SD) (range 55-79) years. Mean plasma $25-0 H$ vitamin D levels were 14.52 (+/$5.65 \mathrm{SD}) \mathrm{ng} / \mathrm{ml}$ at baseline and 47.58 (+/$15.05 \mathrm{SD}) \mathrm{ng} / \mathrm{ml}$ after three months of supplementation.

At the end of the trial there was a statistical significant decrease in both the neurotrophins. NGF plasma levels were respectively: $451.13(+/-243.20 \mathrm{SD}) \mathrm{pg} / \mathrm{ml}$ at baseline and 323.68 (+/- $195.60 \mathrm{SD})$ $\mathrm{pg} / \mathrm{ml}$ after three months (t $(15)=2.05$, $\mathrm{p}=0.05)$; BDNF plasma levels were 431.10 $(+/-182.21$ SD) $\mathrm{pg} / \mathrm{ml}$ at baseline and $366.25(+/-142.75 \mathrm{SD}) \mathrm{pg} / \mathrm{ml}$ after three months $(\mathrm{t}(16)=2.39, \mathrm{p}=0.02)$. Scatterplots of basal and three months values of NGF and BDNF after calcifediol treatment are reported in figures 1 and 2 .

WMS-R "memory quotient" scored meanly $97.00(+/-13.54$ SD) at baseline and 107.82 $(+/-16.19$ SD) after three months of treatment, showing a statistical significant 
improvement compared to baseline ( $\mathrm{t}(16)$

$=-3.49, \mathrm{p}=0.003)$, with a large effect size $(\mathrm{z}$ $-2.95 ; \mathrm{r}=.50$ ) (table 1 ).
No side-effects were reported. Three subjects, out of 20 , were lost to follow up.

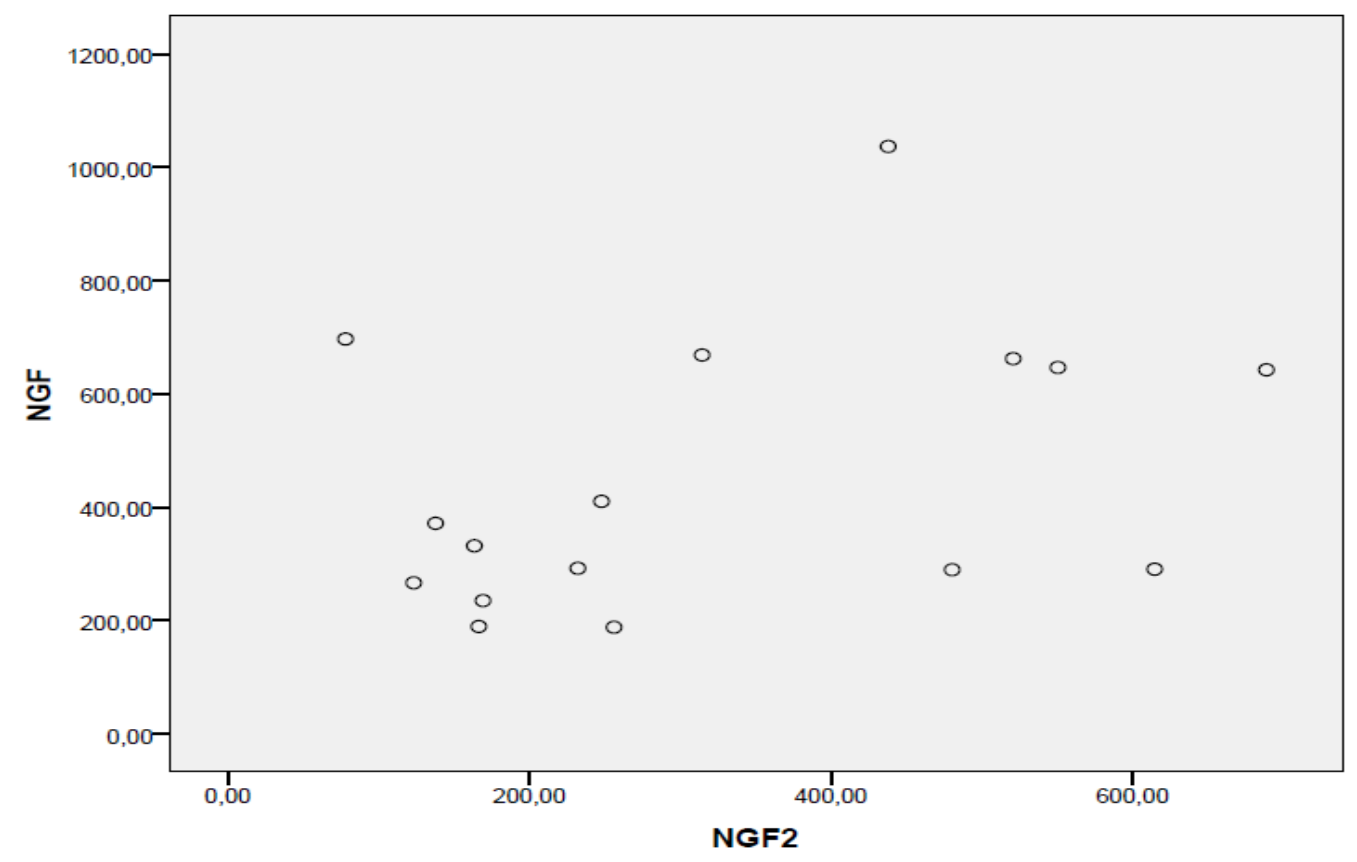

Figure 1: Basal and three months values of NGF after calcifediol treatment (NGF - NGF 2)

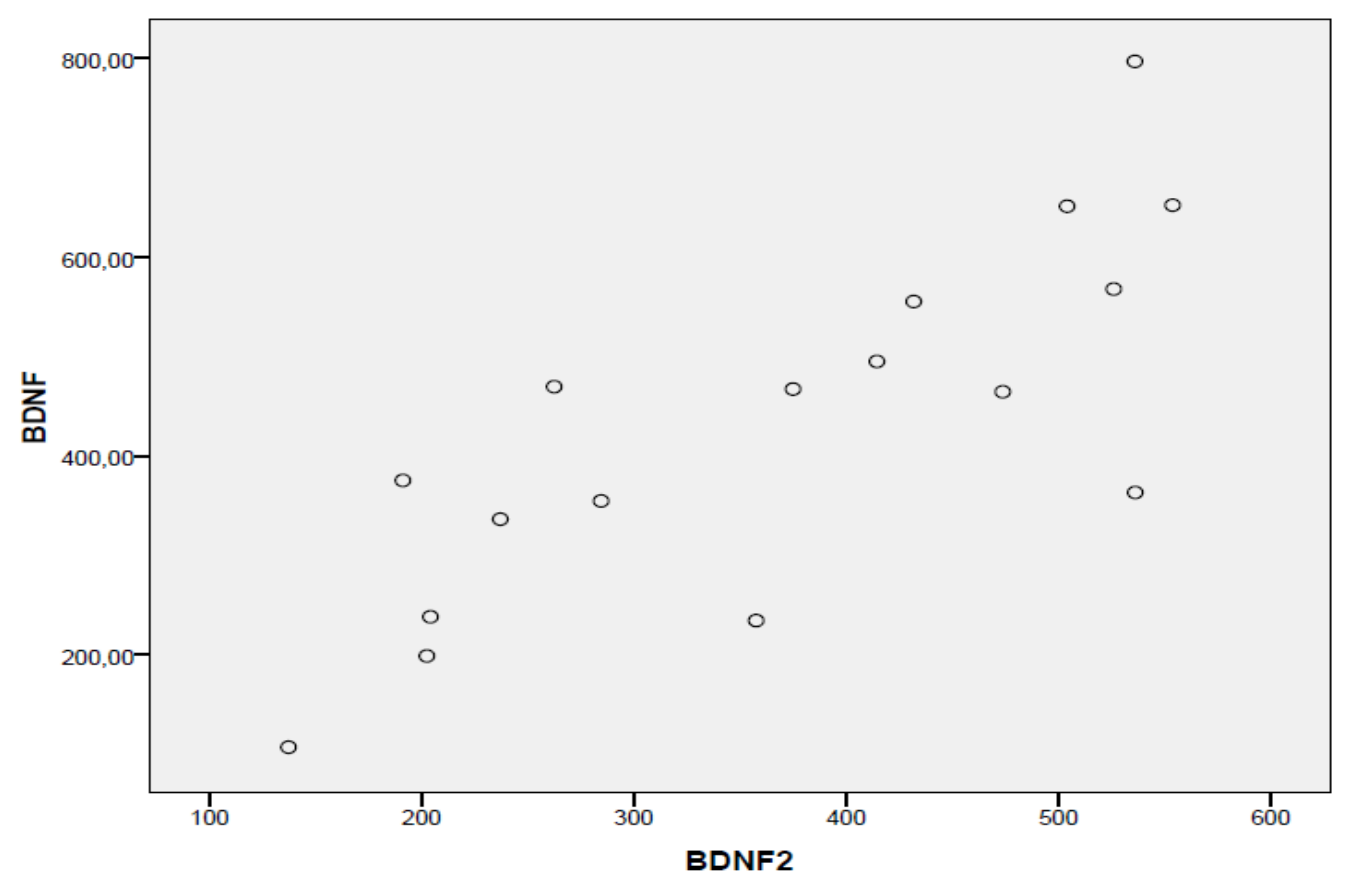

Figure 2: Basal and three months values of BDNF after calcifediol treatment (BDNF - BDNF 2) 
Table 1: Mean (+/- standard deviation) changes between baseline and after three months of calcifediol supplementation for NGF, BDNF and Wechsler Memory Scale; $p$ value for statistical significance

\begin{tabular}{|l|c|c|c|}
\hline & Baseline & 3rd month & p value \\
\hline NGF (pg/ml) & $451.13(+/-243.20 \mathrm{SD})$ & $323.68(+/-195.60 \mathrm{SD})$ & 0.05 \\
\hline BDNF (pg/ml) & $431.10(+/-182.21 \mathrm{SD})$ & $366.25(+/-142.75 \mathrm{SD})$ & 0.02 \\
\hline Wechsler Memory Scale & $97.00(+/-13.54 \mathrm{SD})$ & $107.82(+/-16.19 \mathrm{SD})$ & 0.003 \\
\hline
\end{tabular}

\section{Discussion}

We found that winter vitamin D supplementation to healthy postmenopausal women with scarce levels of circulating $25-\mathrm{OH}$ vitamin $\mathrm{D}$ determines a significant reduction of both NGF and BDNF plasma levels and in line with epidemiological studies, a strong effect on memory and cognitive functions, as measured by means of the WMS-R. Noteworthy, it has been demonstrated that cobalamin (vitamin B12) deficiencyinduced down regulation of P75 immunoreactive cell levels, increases NGF levels in the rat central nervous system and plays a noxious role in the progression of the related neuropathological morphological alterations (Scalabrino et al., 2006; Mutti et al., 2007). The decrease in NGF and BDNF observed in our study could be due to a higher use or uptake. Indeed, vitamin D3 stimulates the expression of P75NTR, the neurotrophin low-affinity receptor, and leads to a decrease in the level of P75NTR mRNA in the spinal cord (Naveilhan et al., 1996). Therefore, it can be speculated that in these models alteration or damage in the central nervous system may be related to the inability to modulate the synthesis of neurotrophic agents in various directions.

In a recent study Molendicjk et al. (2012) found a strong indication for a seasonal pattern in serum BDNF concentrations such that serum BDNF concentrations were, on average, lower in the months January to May and higher in the months June to December with a nadir in March and a peak in September. Maybe, in our study, baseline higher levels of neurotrophins respect to those measured after vitamin D administration reflect a physiological expression due to scarcity of the neurohormone, overcoming the seasonal variations. This observation is in line with Vaynman et al., (2006) who have shown that in rat hippocampus vitamin D decreased exercise-induced BDNF and abolished the BDNF downstream signal transduction cascade important for learning and memory. Considering that both NGF and BDNF are VDR regulated proteins affected by VDR suppression, our results can be explained by the fact that in a condition of paucity of vitamin D, its supplementation plays a crucial role in the modulation of neurotrophic factors that may reflect a compensatory mechanism.

Currently, it is not clear whether vitamin D mediated regulation of neurotrophin is caused by direct transcriptional effect or by another mechanism related to neurotrophin production or release. Silencing of the VDR leads to downregulation of NGF in cortical neurons, suggesting that inefficient utilization of vitamin D may cause a reduction of NGF in neurons during the aging process (GezenAk et al., 2011). We do not know how peripheral neurotrophin levels relate to brain function. By the way, the in vivo activity by vitamin $\mathrm{D}$ results in something more complex respect to the in vitro induction of neurotrophin.

Confirming animal studies (McCann and James, 2008) we can assume that low levels of circulating vitamin D in humans may cause cognitive decline in subjects not affected by neurological impairment and this can be reversed by vitamin D substitution therapy, even if we cannot state how neurotrophin levels are relevant to this process. In facts, it must be taken into account that postmenopausal women, as well as amenorrhoeic subjects, showed lower plasma BDNF levels compared to 
fertile females, with BDNF positively correlated with estradiol and progesterone and negatively with menopausal age (Begliuomini et al., 2007). Reduced plasma BDNF levels are reported to be associated with cognitive impairment in both postmenopausal women (Komulainen et al., 2008) and dementia patients (Lee et al., 2009).

The open design of the study is the major limitation of this trial; a control group would have improved the study. Nonetheless, in this model, the clear-cut action of chronic vitamin D supplementation on NGF and BDNF plasma levels is strongly relevant. In any case, we lack long-term data and our observation is limited to the short period of the trial. A recent study demonstrated that free and bioavailable vitamin D are more strongly correlated with bone mass density than the normally measured total 25-OH D levels (Powe et al, 2011) and we cannot exclude a peculiar action of these fractions on neurotrophins and/or cognition. This is an important finding for its implications in the action of the hormone in different conditions of environment and life, including age, sex and different illnesses.

Vitamin D and some metabolically active precursors modulate the synthesis of neurotrophin, thus, neurons could therefore be vulnerable to aging and neurodegeneration when there is a longterm, or permanent, inefficient utilization or paucity of the hormone. The role played by vitamin $D$ in calcium metabolism and in neurotrophic factors regulation appears to be essential to brain function, as well as the role played by NGF, a neuronal survival molecule that can potentially be used to treat neurodegenerative diseases (Tuszynski et al., 2005). Future studies should continue to explore the relationship between vitamin $\mathrm{D}$ actions and health outcomes.

\section{References}

1.Aloe, L. Properzi, F. Probert, L. Akassoglou, K. Kassiotis, G. Micera, A. and Fiore, M. (1999) "Learning abilities, NGF and BDNF brain levels in two lines of TNF-alpha transgenic mice, one characterized by neurological disorders, the other phenotypically normal." Brain Research, 840 125-137.

2. Annweiler, C. Schott, A.M. Allali, G. Bridenbaugh, S.A. Kressig, R.W. Allain, P. Herrmann, F.R. and Beauchet, 0 . (2010) "Association of vitamin D deficiency with cognitive impairment in older women: cross-sectional study." Neurology, 74 27-32.

3. Barnard, K. and Colon-Emeric, C. (2010) "Extraskeletal effects of vitamin D in older adults: cardiovascular disease, mortality, mood and cognition." American Journal of Geriatric Pharmacotherapy, 8 (1) 4-33.

4. Begliuomini, S. Casarosa, E. Pluchino, N. Lenzi, E. Centofanti, M. Freschi, L. Pieri, M. Genazzani, A.D. Luisi, S. and Genazzani, A.R. (2007) "Influence of endogenous and exogenous sex hormones on plasma brain-derived neurotrophic factor." Human Reproduction, 22 (4) 995-1002.

5. Bishoff-Ferrari, H.A. Dawson-Hughes, B. Willett, W. Staehelin, H.B. Bazemore, M.G. Zee, R.Y. and Wong, J.B. (2004) "Effect of Vitamin D on falls: a metaanalysis". Journal of the American Medical Association, 291 (16) 19992006.

6. Bishoff-Ferrari, H.A. Willett, W.C. Wong, J.B. Giovannucci, E. Dietrich, T. and Dawson-Hughes, B. (2005) "Fracture prevention with vitamin D supplementation: a meta-analysis of randomised controlled trials". Journal of the American Medical Association, 293 (18) 2257-2264.

7. Bischoff-Ferrari, H.A., Dawson-Hughes, B., Stocklin, E. Sidelnikov, E. Willett, W.C. Orav, E.J. Stähelin, H.B. Wolfram, S. Jetter, A. Schwager, J. Henschkowski, J. von Eckardstein, A. and Egli, A. (2012) "Oral Supplementation with 25(OH)D3 versus vitamin D3: effects on $25(\mathrm{OH}) \mathrm{D}$ 
levels, lower extremity function, blood pressure, and markers of innate immunity". Journal of Bone and Mineral Research, 27 (1) 160-169.

8. Brannon, P.M. Yetley, E.A. Bailey, R.L. and Picciano, M.F. (2008) "Overview of the conference "Vitamin D and Health in the 21st Century: an Update,". American Journal of Clinical Nutrition, 88 (2) 483S490S.

9. Buell, J.S. Scott, T.M. Dawson-Hughes, B. Dallal, G.E. Rosenberg, I.H. Folstein, M.F. and Tucker, K.L. (2009) "Vitamin D is associated with cognitive function in elders receiving home health services". Journals of Gerontology. Series A: Biological Sciences and Medical Sciences, 64 888-895.

10.Buell, J.S. Dawson-Hughes, B. Scott, T.M. Weiner, D.E. Dallal, G.E. Qui, W.Q. Bergethon, P. Rosenberg, I.H. Folstein, M.F. Patz, S. Bhadelia, R.A. and Tucker, K.L. (2010) "25-Hydroxyvitamin D, dementia, and cerebrovascular pathology in elders receiving home services". Neurology, 74 18-26.

11.Cekic, M. Sayeed, I. and Stein, D.G. (2009) "Combination treatment with progesterone and vitamin D hormone may be more effective than monotherapy for nervous system injury and disease". Frontiers in Neuroendocrinology, 30 158-172.

12.Dursun, E. Gezen-Ak, D. and Yilmazer, S. (2011) "A novel perspective for Alzheimer's disease: vitamin D receptor suppression by Amyloid-b and preventing the Amyloid-b induced alterations by vitamin D in cortical neurons". Journal of Alzheimer Disease, 23 207-219.

13.Evles, D. Mackay-Sim, A. Mc Grath, J. and Feron, F. (2003). "Vitamin D3 and brain development". Neuroscience, 118 (3) 641-653.

14.Evles, D. Almeras, L. Benech, P. Patatian, A. Mackay-Sim, A. McGrath, J. and Féron, F. (2007) "Developmental vitamin D deficiency alters the expression of genes encoding mitochondrial, cytoskeletal and synaptic proteins in the adult rat brain". Journal of Steroid Biochemistry and Molecular Biology, 103 (3-5) 538545.

15.Eyles, D.W. Smith, S. Kinobe, R. Hewison, M. and McGrath, J.J. (2005) "Distribution of the vitamin D receptor and 1-alpha hydroxylase in human brain". Journal of Chemical Neuroanatomy, 29 21-30.

16.Eyles, D.W. Feron, F. Cui, X. Kesby, J.P. Harms, L.H. Ko, P. McGrath, J.J. and Burne, T.H. (2009) "Developmental vitamin $\mathrm{D}$ deficiency causes abnormal brain development". Psychoneuroendocrinology, 34 Suppl 1 S247-S257.

17.Feron, F. Burne, T.H. Brown, J. Smith, E. McGrath, J.J. Mackay-Sim, A. and Eyles, D.W. (2005) "Developmental Vitamin D3 deficiency alters the adult rat brain". Brain Research Bullettin, 15 65 (2) 141-148.

18.Garcion, E. Wion-Barbot, N. MonteroMenei, C.N. Berger, F. and Wion, D. (2002) "New clues about vitamin D functions in the nervous system". Trends in Endocrinology and Metabolism, 13 (3) 100-105.

19.Gascon Barre, and M. Huet, P.M. (1983) "Apparent (3H) 1,25 hydroxyvitamin D3 uptake by canin and rodent brain". American Journal of Physiology Endocrinology and Metabolism, 244 E266-E271.

20.Genant, H.K. Cooper, C. Poor, G. Reid, I. Ehrlich, G. Kanis, J. Nordin, B.E. Barrett-Connor, E. Black, D., Bonjour, J.P. Dawson-Hughes, B. Delmas, P.D. Dequeker, J. Ragi Eis. S. Gennari, C. Johnell, O. Johnston, C.C. Jr. Lau, E.M. Liberman, U.A. Lindsay, R. Martin, T.J. Masri, B. Mautalen, C.A. Meunier, P.J. Khaltaev, N. et al. (1999) "Interim Report and Recommendations of the World Health Organization Task-Force 
for Osteoporosis". Osteoporosis International, 104 259-264.

21.Gezen-Ak, D. Dursun, E. and Yilmazer, S. (2011) "The effects of vitamin D receptor silencing on the expression of LVSCC-A1C and LVSCC-A1D and the release of NGF in cortical neurons". PLoS one, 6 (3) 1-10.

22.Henry, H.L. Bouillon, R. Norman, A.W. Gallagher, J.C. Lips, P. Heaney, R.P. Vieth, R. Pettifor, J.M. Dawson-Hughes, B. Lamberg-Allardt, C.J. and Ebeling, P.R. (2010) "14th Vitamin D Workshop consensus on vitamin D nutritional guidelines". Journal of Steroid Biochemistry and Molecular Biology, 121 (1-2) 4-6.

23.Haddad, J.G. Jr. and Rojanasathit, S. (1976) "Acute administration of 25hydroxycholecalcifero in man". Journal of Clinical Endocrinology and Metabolism, 42 (2) 284-90.

24.Khazai, N. Judd, S.E. and Tangpricha, V. (2008) "Calcium and vitamin D: skeletal and extraskeletal health". Current Rheumatology Reports, 10 110117.

25.Komulainen, P. Pedersen, M. Hänninen, T. Bruunsgaard, H. Lakka, T.A. Kivipelto, M. Hassinen, M. Rauramaa, T.H. Pedersen, B.K. and Rauramaa R. (2008) "BDNF is a novel marker of cognitive function in ageing women: the DR's EXTRA Study". Neurobiology of Learning Memory, 90 (4) 596-603.

26.Kuningas, M. Mooijaart, S.P. Jolles, J. Slagboom, P.E. Westendorp, R.G.J. and van Heemst, D. (2009) "VDR gene variants associate with cognitive function and depressive symptoms in old age". Neurobiology of Aging, 30 466-473.

27.Larrosa, M. Gratacos, J. Vaqueiro, M. Prat, M. Campos, F. Larrosa, M. and Roqué, M. (2001) "Prevalence of hypovitaminosis D in elderly institutionalized residents: influence of a substitutive treatment". Meicina Clinica (Barc), 117 611-614.
28.Lee, D.M. Tajar, A. Ulubaev, A. Pendleton, N. O’Neill, T.W. O'Connor, D.B. Bartfai, G. Boonen, S. Bouillon, R. Casanueva, F.F. Finn, J.D. Forti, G. Giwercman, A. Han, T.S. Huhtaniemi, I.T. Kula, K. Lean, M.E. Punab, M. Silman, A.J. Vanderschueren, D. and Wu, F.C. EMAS study group. (2009) "Association between 25hydroxyvitamin D levels and cognitive performance in middle-aged and older European men". Journal of Neurology, Neurosurgery and Psychiatry, 80 722729.

29.Lee, J.G. Shin, B.S. You, Y.S. Kim, J.E. Yoon, S.W. Jeon, D.W. Baek, J.H. Park, S.W. and Kim, Y.H. (2009) "Decreased serum brain-derived neurotrophic factor levels in elderly korean with dementia". Psychiatry Investigation, 6 (4) 299-305.

30.Liewellyn, D.J. Langa, K.M. and Lang, I.A. (2009) "Serum 25-hydroxyvitamin D concentration and cognitive impairment". Journal of Geriatric Psychiatry and Neurology, 22 (3)188195.

31.Liewellyn, D.J. Lang, I.A. Langa, K.M. Muniz Terrera, G. Phillips, C.L. Cherubini, A. Ferrucci, L. and Melzer, D. (2010) "Vitamin D and risk of cognitive decline in elderly persons". Archives of Internal Medicine, 170 1135-1141.

32.Liewellyn, D.J. Lang, I.A. Langa, K.M. and Melzer, D. (2011) "Vitamin D and cognitive impairment in the elderly US population". Journals of Gerontology. Series A: Biological Sciences and Medical Sciences, 66A (1) 59-65.

33.Lisak, R.P. Benjamins, J.A. Bealmear, B. Nedelkoska, L. Studzinski, D. Retland, E. Yao, B. and Land, S. (2009) "Differential effects on ThI, monocyte/macrophage and Th2 cytokine mixtures on early gene expression for molecules associated with metabolism, signalling and regulation in central nervous system mixed glial cell cultures". Journal of Neuroinflammation, 6, 4. 
34.McCann, J.C. and Ames, B.N. (2008). "Is there convincing biological or behavioural evidence linking vitamin D deficiency to brain dysfunction?" Journal of the Federation of American Societies for Experimental Biology. 22 982-1001.

35.McGrath, J. Feron, F. Eyles, D. and Mackay-Sim, A. (2001) "Vitamin D: the neglected neurosteroid?" Trends in Neurosciences, 24 570-572.

36.Molendijk, M.L. Haffmans , J.P.M. Bus, B.A.A. Spinhoven, P. Penninx, B.W.J.H. Prickaerts, J. Oude Voshaar, R.C. and Elzinga,B.M. (2012) "Serum BDNF Concentrations Show Strong Seasonal Variation and Correlations with the Amount of Ambient Sunlight". PLoS one 7(11): e48046.

37.Mutti, E. Veber, D. Stampachiacchere, B. Triaca, V. Gammella, E. Tacchini, L. Aloe, and L. Scalabrino, G. (2007). "Cobalamin deficiency-induced downregulation of p75-immunoreactive cell levels in rat central nervous system". Brain Research, 1157 92-99.

38. Naveilhan P. Neveu I. Baudet C. Funakoshi H. Wion D. Brachet P. and Metsis M. (1996). "1,25Dihydroxyvitamin D3 regulates the expression of the low-affinity neurotrophin receptor". Brain Research Molecular Brain Research 41 (1-2) 259268.

39.Neveu I. Naveilhan P. Jehan F. Baudet C. Wion D. De Luca H.F. and Brachet P. (1994) "1,25-Dihydroxyvitamin D3 regulates the synthesis of nerve growth factor in primary cultures of glial cells". Brain Research Molecular Brain Research, 24 (1-4) 70-76.

40.Neveu, I. Naveilhan, P. Menaa, C. Wion, D. Brachet, P. and Garabédian, M. (1994) "Synthesis of 1,25dihydroxyvitamin D3 by rat brain macrophages in vitro". Journal of Neuroscience Research, 38, 214-220.
41.Papadimitroupolos, E. Wells, G. Shea, B. Gillespie, W. Weaver, B. Zytaruk, N. Cranney, A. Adachi, J. Tugwell, P. Josse, R. Greenwood, C. and Guyatt, G. Osteoporosis Methodology Group and the Osteoporosis Research Advisory Group. (2002) "Meta-analysis of the effect of vitamin D treatment in preventing osteoporosis in postmenopausal women". Endocrine Reviews, 23 (4) 560-569.

42.Powe, C.E. Ricciardi, C. Berg, A.H. Erdenesanaa, D. Collerone, G. Ankers, E. Wenger, J. Karumanchi, S.A. Thadhani, R. and Bhan, I. (2011) "Vitamin D binding protein modifies the vitamin D-bone mineral density relationship" Journal of Bone Mineral Research, 26 (7) 1609-1616.

43.Przybelski, R.J. and Binkley, N.C. (2007) "Is vitamin D important for preserving cognition? A positive correlation of serum 25hydroxyvitamin D concentration with cognitive function". Archives of Biochemistry and Biophysics, 460 (2) 202-205.

44.Scalabrino, G. Mutti, E. Daniela Veber, D. Aloe, L. Corsi, M.M. Galbiati, S. and Tredici, G. (2006) "Increased spinal cord NGF levels in rats with cobalamin (vitamin $\mathrm{B}_{12}$ ) deficiency". Neuroscience Letters, 396 (2) 153-158.

45.Siegel, G.J. and Chauhan, N.B. (2000) "Neurotrophic factors in Alzheimer and Parkinson's disease brain". Brain Research Reviews, 33 199-227.

46.Slinin, Y. Paudel, M.L. Taylor, B.C. Fink, H.A. Ishani, A. Canales, M.T. Yaffe, K. Barrett-Connor, E. Orwoll, E.S. Shikany, J.M. Leblanc, E.S. Cauley, J.A. and Ensrud, K.E. Osteoporotic Fractures in Men (MrOS) Study Research Group. (2010) "25hydroxyvitamin D levels and cognitive performance and decline in elderly men". Neurology, 74 33-41. 

47.Stamp, T.C. (1974) "Intestinal absorption of 25- hydroxycholecalciferol". Lancet, 2 (7873) 121-123.

48.Staud, R. (2005)"Vitamin D: more than just affecting calcium and bone". Current Rheumatology. Reports, 7 (5) 356-364.

49.Tuszynski, M.H., Thal, L. Pay, M. Salmon, D.P. Sang, U.H. Bakay, R. Patel, P. Blesch, A. Vahlsing, H.L. Ho, G. Tong, G. Potkin, S.G. Fallon, J. Hansen, L. Mufson, E.J. Kordower, J.H. Gall, C. and Conner, J. (2005) "A phase 1 clinical trial of nerve growth factor gene therapy for Alzheimer disease". Nature Medicine, 11 551-555.

50.Vaynman, S. Ying, Z. Wu, A. and GomezPinilla, F. (2006) "Coupling energy metabolism with a mechanism to support brain-derived neurotrophic factor-mediated plasticity". Neuroscience, 139 (4) 1221-1234.
51.Wechsler, D. (1945) "Wechsler Memory Scale. A standardized memory scale for clinical use". Journal of Psychology, 18 87-95.

52.Wechsler, D. (1987) "Wechsler Memory Scale-Revised manual". New York: Psychological Corp.

53.Weskamp G. and Otten U. (1987) "An enzyme-linked immunoassay for nerve growth factor (NGF): a tool for studying regulatory mechanisms involved in NGF production in brain and in peripheral tissues". Journal of Neurochemistry, 48 1779-1786.

54.Wilkins, C.H. Sheline, Y.I. Roe, C.M. Birge, S.J. and Morris, J.C. (2006) "Vitamin D deficiency is associated with low mood and worse cognitive performance in older adults". American Journal of Geriatric Psychiatry, 14 1032-1040. 